\title{
Screening of Lentil (Lens culinaris Medik.) Genotypes and Correlation Analysis under PEG Imposed Water Stress Condition
}

\author{
Asit Prasad Dash ${ }^{1 *}$, Dilip Kumar De ${ }^{2}$, Soumitra Mohanty ${ }^{3}$ and Devraj Lenka ${ }^{4}$ \\ ${ }^{1 \& 4}$ Dept. of Plant Breeding \& Genetics, OUAT, BBSR, Odisha (751 003), India \\ ${ }^{2}$ Dept. of Genetics \& Plant Breeding, BCKV, Mohanpur, West Bengal (741 252), India \\ ${ }^{3}$ Agriculture and Farmers' Empowerment Dept., Government of Odisha (767 020), India
}

\author{
Corresponding Author \\ Asit Prasad Dash \\ e-mail: dashpraasit@gmail.com
}

\author{
Article History \\ Article ID: AR1829c \\ Received in $27^{\text {th }}$ July, 2017 \\ Received in revised form $30^{\text {th }}$ July, 2017 \\ Accepted in $7^{\text {th }}$ August, 2017
}

\begin{abstract}
The present experiment was carried out at the Department of Genetics and Plant Breeding, Bidhan Chandra Krishi Viswavidyalaya, West Bengal, India to screen lentil (Lens culinaris Medik.) genotypes for drought tolerance at seedling stage and to study the correlation among the seedling traits. For this purpose forty eight genotypes of lentil collected from AICRP on MULLaRP, Kalyani centre, Bidhan Chandra Krishi Viswavidyalaya, Nadia were evaluated for drought tolerance at seedling stage following slant glass plate method under pre-standardized -9.0 bar external water potential imposed by polyethylene glycol ( $\mathrm{MW}-6000)$ against control ( 0.0 bar). The experiment was laid out in an asymmetrical factorial completely randomized design with three replications. Data from six randomly selected competitive seedlings on eleven growth parameters viz., root length $(\mathrm{cm})$, shoot length $(\mathrm{cm})$, total length $(\mathrm{cm})$, root fresh weight $(\mathrm{mg})$, shoot fresh weight $(\mathrm{mg})$, leaf fresh weight $(\mathrm{mg})$, total fresh weight $(\mathrm{mg})$, root dry weight $(\mathrm{mg})$, shoot dry weight $(\mathrm{mg})$, leaf dry weight (mg) and total dry weight $(\mathrm{mg})$ were recorded from ten days old seedlings from both control and treatment plate through destructive sampling. All the forty eight genotypes showed variable relative reduction \% for all root and shoot traits under polyethylene glycol imposed water stress. Basing on drought tolerance efficiency, relative reduction \% and the seedling growth parameters the genotypes were categorized as susceptible and tolerant to drought stress. Among the forty-eight genotypes, PL-406 (94.667\%) exhibited the highest drought tolerance efficiency while L1112-20 (65.269\%) exhibited the lowest drought tolerance efficiency. Correlation analysis revealed that, total dry weight attained a strong positive significant association with root dry weight followed by total fresh weight. All the traits except root length and total length attained significant positive correlation with total dry weight. Total fresh weight exhibited a higher direct effect on total dry weight which is the measure of drought tolerance at seedling stage.
\end{abstract}

Keywords: Correlation, drought stress, lentil, PEG, screening, seedling stage

\section{Introduction}

Among all factors limiting crop productivity, drought remains single one important factor affecting the world security and sustainability in agricultural production (Farshadfar et al., 2012). Global water scarcity and increases in demand for non-agricultural uses of water, expansion of the area under irrigation in developing countries does not appear to be a realistic scenario to address the challenge of food security. Therefore, food security in the twenty-first century will rely increasingly on the release of cultivars with improved potentiality to combat drought and with high yield stability (Luo, 2010; Chapman et al., 2012). The response of plants to low water potential is complex and involves changes in the morphology, physiology and metabolism (Mbarek et al., 2013). The evaluation of crops at seedling stage is an important aspect of crop breeding programme even with an objective to evolve drought tolerant varieties (Dhanda et al., 2004; Singh et al., 2017).

Lentil (Lens culinaris Medik), one of the most ancient annual legumes is grown as an important food source for over 8,000 years (Dhuppar et al., 2012). Lentil plays a significant role in maintenance and improvement of soil fertility by adding nitrogen, carbon and organic matter to the soil, which promotes sustainable cereal based systems of crop production (Sarker and Kumar, 2011). In the Indian subcontinent, lentil is primarily grown in the post-rainy winter season on receding soil moisture, which is bare minimum to meet the normal evapo-transpiration. Thus, the crop invariably suffers from moisture stress of varying degrees during different stages of growth affecting various physiological processes associated with normal crop growth and development. As a result, drought has emerged as the major yield constraint in lentil 
throughout its production range (Fouad et al., 2011). Hence, though India ranks first in total area under lentil cultivation (1.8 $\mathrm{mha})$, it comes second after Canada in respect of production $(1.1 \mathrm{mt})$, while lagging much behind in the race of productivity (611 $\mathrm{kg} \mathrm{ha}^{-1}$ as against $1067 \mathrm{~kg} \mathrm{ha}^{-1}$ ) (FAOSTAT, 2014). Thus, one of the challenges in lentil breeding is to evolve genotypes with higher seed yield under water deficit conditions. PEG-based in vitro screening for drought tolerance has been proven to be a suitable method to effectively screen large sets of germplasm with good accuracy (Kulkarni \& Deshpande, 2007). Hence, the present experiment was conducted to identify drought tolerant and susceptible genotypes in relation to biomass production at early seedling growth stage under selected level of -9.0 bar external water potential imposed by PEG-6000 and to correlate the seedling traits to analyze the interdependence among them.

\section{Materials and Methods}

Seeds of forty-eight lentil genotypes collected from AICRP on MULLaRP, Kalyani centre, Bidhan Chandra Krishi Viswavidyalaya, Nadia were evaluated for drought tolerance at seedling stage during first week of November, to last week of January for 2 consecutive years (2013-14, 2014-15). The experiment was carried out following slant glass plate method in the laboratory of the Department of Genetics and Plant Breeding, B.C.K.V., under pre-standardized -9.0 bar external water potential imposed by polyethylene glycol (MW-6000) against control (0.0 bar) following an asymmetrical factorial completely randomized design with three replications. The geographical location of the site of experiment is $23^{\circ} \mathrm{N}$ latitude, $89^{\circ} \mathrm{E}$ longitude and $9.75 \mathrm{~m}$ altitude above the mean sea level.

Seventy two healthy, viable seeds of each lentil genotype were surface sterilized by immersing the seeds in $70 \%$ ethanol for 2 minutes followed by thorough washing with distilled water. Twelve seeds of a genotype were arranged in a row with even space over a glass plate $\left(20 \times 30 \mathrm{~cm}^{2}\right)$ wrapped with a blotting paper. To prevent the seeds from sliding down when the set was kept in a slant position in a stand, another glass strip $\left(20 \times 2 \mathrm{~cm}^{2}\right)$ was placed over the seeds with the help of a piece of thermocol at the two ends and guarder in such a way that the seeds remained in their position and the seedlings grew without any hindrance. The whole set was then placed in a transparent polythene bag. There were six such sets for each genotype representing three replications for control and three replications for treatment. In the treatment plates, PEG solution of desired water potential was used as germinating medium, while in the control plates pure distilled water was used for the purpose. The seeds were then allowed to germinate and grow for 10 days under indoor laboratory condition under sufficient light, $70-80 \%$ relative humidity $(\mathrm{RH})$ and at a temperature range of $20-25{ }^{\circ} \mathrm{C}$. Data from six randomly selected competitive seedlings on the following growth parameters viz., root length $(\mathrm{cm})$, shoot length $(\mathrm{cm})$, total length $(\mathrm{cm})$, root fresh weight $(\mathrm{mg})$, shoot fresh weight $(\mathrm{mg})$, leaf fresh weight $(\mathrm{mg})$, total fresh weight $(\mathrm{mg})$, root dry weight (mg), shoot dry weight ( $\mathrm{mg}$ ), leaf dry weight (mg) and total dry weight $(\mathrm{mg})$ were recorded from 10 days old seedlings from both control and treatment plate through destructive sampling.

From the mean values of the above parameters, the following two derived-data i.e. Drought Tolerance Efficiency (DTE) and Relative reduction \% were obtained. Correlation and path analysis wee done using software SPSS16.

(i) To work out the potentiality of each genotype to tolerate drought under a specific EWP, the Drought Tolerance Efficiency (DTE) under each drought stress level was calculated as per Fisher and Maurer (1978) following the formula:

DTE $(\%)=\frac{\text { Total dry weight under treatment }}{\text { Total dry weight under control }} \times 100$

(ii) Due to treatment with PEG solution, the seedling growth was assumed to be affected. Relative reduction of a genotype for a specific trait was computed as below:

$$
\begin{aligned}
& \text { RR\% Mean performance as measured for a } \\
& \text { 1- } \frac{\text { character under drought stess }}{\text { Mean performance as measured for }} \\
& \text { the same character under control }
\end{aligned} \times 100
$$

\section{Results and Discussion}

A reduction in mean values for all the characters in all the genotypes was observed due to imposition of water stress. All the genotypes under study showed differential response in their tolerance to drought stress. The SEm, $\pm C D$ at $(p=0.05)$ and relative reduction $\%$ for different morphological characters from the seedlings are presented in Table 1 and 2 respectively. However, response of individual character is discussed below-

\subsection{Root length}

Serving as interfaces between plant and the soil, roots are much more exposed to drought stress than the upper plant parts. Therefore, the root system can be as affected, or even more affected, than the aerial parts of the plant for drought stress (Franco et al., 2011). Comparative study of the data indicated that drought-stressed seedlings had significantly lower root length as compared to the seedlings under control condition, although absolute values varied from genotype to genotype. When the seedlings were treated with $-9.0 \mathrm{bar}$ PEG solution, it was noticed that, PL-406 recorded the highest mean $(13.293 \mathrm{~cm})$ followed by IPL-324, L1112-17, IPL-221, DL-11-5. Similarly, KLS-107 $(4.711 \mathrm{~cm})$ exhibited the lowest mean under control and treatment respectively. Among all the genotypes, highest relative reduction \% (RRP) was recorded in KLS-107 (56.377\%) that produced the lowest mean for this character under treatment, while least RRP was observed in PL-406 (2.087\%) that produced the highest mean for this character under treatment. The highest reduction recorded in KLS-107, might have made the variety to reveal the lowest mean root length under stress condition. Such difference with 
Table 1: SEm \pm and CD ( $p=0.05)$ value of 11 seedling traits of 48 genotypes of Lentil

\begin{tabular}{|c|c|c|c|c|}
\hline $\begin{array}{l}\text { Charac- } \\
\text { ters }\end{array}$ & & $\begin{array}{l}\text { Geno- } \\
\text { type (G) }\end{array}$ & $\begin{array}{l}\text { Treatment } \\
(T)\end{array}$ & $G \times T$ \\
\hline \multirow[t]{2}{*}{$\mathrm{RL}(\mathrm{cm})$} & SEm \pm & 0.020 & 0.004 & 0.028 \\
\hline & $\mathrm{CD}(p=0.05)$ & 0.055 & 0.011 & 0.078 \\
\hline \multirow[t]{2}{*}{ SL (cm) } & SEm \pm & 0.016 & 0.003 & 0.023 \\
\hline & $\mathrm{CD}(p=0.05)$ & 0.46 & 0.009 & 0.065 \\
\hline \multirow[t]{2}{*}{$\mathrm{TL}(\mathrm{cm})$} & SEm \pm & 0.028 & 0.006 & 0.039 \\
\hline & $\mathrm{CD}(p=0.05)$ & 0.077 & 0.016 & 0.109 \\
\hline \multirow[t]{2}{*}{ RFW (mg) } & SEm \pm & 1.031 & 0.211 & 1.459 \\
\hline & $\mathrm{CD}(p=0.05)$ & 2.879 & 0.588 & 4.072 \\
\hline \multirow[t]{2}{*}{ SFW (mg) } & SEm \pm & 1.079 & 0.220 & 1.526 \\
\hline & $\mathrm{CD}(p=0.05)$ & 3.012 & 0.615 & 4.260 \\
\hline \multirow[t]{2}{*}{ LFW (mg) } & SEm \pm & 0.474 & 0.097 & 0.671 \\
\hline & $\mathrm{CD}(p=0.05)$ & 1.325 & 0.270 & 1.873 \\
\hline \multirow[t]{2}{*}{ TFW (mg } & SEm \pm & 0.997 & 0.204 & 1.410 \\
\hline & $\mathrm{CD}(p=0.05)$ & 2.784 & 0.568 & 3.937 \\
\hline \multirow[t]{2}{*}{ RDW (mg) } & SEm \pm & 0.453 & 0.093 & 0.641 \\
\hline & $\mathrm{CD}(p=0.05)$ & 1.265 & 0.258 & 1.789 \\
\hline \multirow[t]{2}{*}{ SDW (mg) } & SEm \pm & 0.347 & 0.071 & 0.491 \\
\hline & $\mathrm{CD}(p=0.05)$ & 0.969 & 0.198 & 1.370 \\
\hline \multirow[t]{2}{*}{ LDW (mg) } & SEm \pm & 0.18 & 0.044 & 0.308 \\
\hline & $\mathrm{CD}(p=0.05)$ & 0.608 & 0.124 & 0.860 \\
\hline \multirow[t]{2}{*}{ TDW (mg) } & SEm \pm & 0.450 & 0.092 & 0.636 \\
\hline & $C D(p=0.05)$ & 1.256 & 0.256 & 1.777 \\
\hline
\end{tabular}

respect to growth rate may be due to the differential genetic makeup of the different germplasm. Reduced root growth due to treatment has been reported earlier by Nasab (2011) in lentil. The relative reduction of root length under moisture stress could be due to the reduction in the absorption of water and delayed translocation of carbohydrates.

\subsection{Shoot length}

Under control condition, L1112-13 recorded the highest mean value $(8.183 \mathrm{~cm})$ and $\mathrm{L}-100$ recorded the lowest $(3.267$ $\mathrm{cm})$. In case of imposed drought stress condition, L-4591 recorded the highest mean $(5.233 \mathrm{~cm})$ and L1112-20 recorded the lowest $(2.144 \mathrm{~cm})$. The relative reduction was recorded highest (50.228\%) in L1112-20 and lowest (2.041\%) in VL-142. In general the genotypes which exhibited higher mean under treatment had the lower relative reduction. Interestingly, most of the genotypes those exhibited significantly higher mean for root length under control or under treatment, revealed similar result in case of shoot length also. The result further indicated that the root part of some genotypes remained less affected due to treatment but the shoot part was affected more viz., LL-12-10, PL-122, PLG-109, LH-08-10 and K-75. The reverse case was also observed in some genotypes viz., L-4581, L-1112-6, DL-11-4, KLS-113, LH-07-27, ILL-10808 and LL-1114. Reduction in shoot length due to moisture stress was previously reported by Nasab (2011); Salehpour et al. (2009) for lentil. Reduction of shoot length may be due to inhibition of processes like cell division, enlargement and differentiation associated with water deficit. Similar reasons might have played role due to which there was reduction of shoot length in all genotypes under study. It may be noticed that root length was more affected than that of shoot length due to water stress. Selection pressure during variety development might have been given on higher root length due to which, on administration of treatment, the mean values for root length of more number of genotypes reduced.

\subsection{Total length}

In case of forced drought stress, PL-406 exhibited the highest $(18.077 \mathrm{~cm}), \mathrm{KLS}-107$ exhibited the lowest mean value $(7.473$ $\mathrm{cm})$. It may be mentioned here that L1112-13 had the highest shoot length and significantly high root length. It may be noticed here that those genotypes that exhibited significantly higher mean for root length under control or treatment also produced significantly higher mean for total length under respective condition. This may be because of the higher contribution of root length towards total length. Considering relative reduction, the highest reduction in total length (52.119\%) was revealed by the genotype KLS-107, which had highest relative reduction for root length also. Least reduction (5.552\%) was revealed by the genotype IPL-324.

\subsection{Root fresh weight}

Considering the character root fresh weight under control, DPL62 revealed the highest mean $(493 \mathrm{mg}$ ) and LP-112 revealed the lowest $(195.667 \mathrm{mg})$. However, in case of treatment, PLG-109 revealed the highest $(444 \mathrm{mg})$ and the genotype LP-112 revealed the lowest $(140.333 \mathrm{mg})$. All the genotypes witnessed a significant reduction in root fresh weight due to the imposition of water stress, but the highest reduction $(47.044 \%)$ was recorded in the genotype KLS-113, while the lowest reduction (3.738\%) was in LH-08-10. Maryam et al. (2013) also reported reduction in root fresh weight because of imposition of water stress. Significant reduction of root fresh weight due to water stress reveals that selection pressure for the development of varieties has been applied for the higher root fresh weight. Morphological effects in growth may be the secondary manifestation of primary events, caused by variety of more specific effects acting at the cellular or molecular level in the receiver plants. A most common damaging effect of low moisture level or low water potential is the decline in fresh biomass and dry matter production. This decrease is because of the production of reduced photosynthates under water deficit conditions. Water deficit upsets normal turgor pressure and it would lead to loss of cell turgidity that may stop cell enlargement causing reduced plant growth and the pattern of 


\begin{tabular}{|c|c|c|c|c|c|c|c|c|c|c|c|c|}
\hline Genotypes & $\begin{array}{c}\mathrm{RL} \\
(\mathrm{cm})\end{array}$ & $\begin{array}{l}\mathrm{SL} \\
(\mathrm{cm})\end{array}$ & $\begin{array}{c}\mathrm{TL} \\
(\mathrm{cm})\end{array}$ & $\begin{array}{l}\text { RFW } \\
\text { (mg) }\end{array}$ & $\begin{array}{l}\text { SFW } \\
\text { (mg) }\end{array}$ & $\begin{array}{l}\text { LFW } \\
\text { (mg) }\end{array}$ & $\begin{array}{l}\text { TFW } \\
\text { (mg) }\end{array}$ & $\begin{array}{l}\text { RDW } \\
\text { (mg) }\end{array}$ & $\begin{array}{l}\text { SDW } \\
\text { (mg) }\end{array}$ & $\begin{array}{l}\text { LDW } \\
\text { (mg) }\end{array}$ & $\begin{array}{l}\text { TDW } \\
\text { (mg) }\end{array}$ & DTE \% \\
\hline L1112-13 & 27.17 & 40.60 & 31.76 & 26.42 & 27.92 & 27.27 & 27.07 & 17.24 & 21.67 & 29.63 & 20.69 & 79.310 \\
\hline LL-12-10 & 20.53 & 42.94 & 28.58 & 21.25 & 46.04 & 36.23 & 31.40 & 9.09 & 20.29 & 35.71 & 18.10 & 81.905 \\
\hline LP-112 & 19.69 & 11.65 & 17.49 & 28.28 & 47.85 & 30.30 & 37.04 & 20.00 & 45.61 & 30.77 & 31.76 & 68.243 \\
\hline LL-1231 & 19.62 & 7.80 & 16.76 & 20.94 & 18.60 & 24.27 & 20.46 & 15.39 & 20.00 & 18.52 & 7.42 & 82.581 \\
\hline IPL-322 & 25.36 & 37.98 & 28.86 & 21.52 & 35.85 & 35.20 & 26.83 & 14.53 & 30.51 & 30.77 & 21.86 & 78.140 \\
\hline PL-122 & 10.20 & 41.99 & 21.10 & 20.25 & 14.73 & 22.22 & 18.67 & 16.90 & 11.11 & 25.93 & 16.78 & 83.217 \\
\hline L1112-7 & 22.88 & 15.37 & 20.56 & 16.22 & 22.08 & 36.28 & 21.33 & 7.58 & 9.80 & 35.71 & 15.72 & 84.277 \\
\hline PL-406 & 2.09 & 15.09 & 5.90 & 5.64 & 10.02 & 10.30 & 7.65 & 5.00 & 6.00 & 5.00 & 5.33 & 94.667 \\
\hline DL-11-5 & 16.67 & 17.39 & 16.82 & 11.01 & 11.11 & 9.03 & 10.83 & 11.24 & 12.77 & 29.17 & 14.38 & 85.625 \\
\hline ILL-10803 & 28.20 & 41.43 & 31.66 & 26.25 & 27.17 & 36.72 & 27.87 & 25.74 & 30.51 & 38.46 & 29.65 & 70.352 \\
\hline L1112-6 & 33.62 & 17.43 & 29.70 & 32.73 & 13.94 & 22.97 & 25.19 & 15.15 & 8.51 & 25.93 & 15.00 & 85.000 \\
\hline L112-9 & 19.81 & 15.19 & 18.80 & 6.95 & 19.02 & 15.89 & 12.34 & 5.95 & 20.76 & 18.52 & 12.81 & 87.195 \\
\hline L-1112-11 & 12.74 & 6.99 & 11.31 & 22.52 & 21.59 & 23.39 & 22.37 & 19.77 & 21.43 & 27.27 & 21.74 & 78.261 \\
\hline L1112-12 & 34.77 & 23.68 & 32.07 & 17.74 & 25.54 & 28.57 & 21.60 & 12.35 & 15.39 & 28.95 & 17.09 & 82.911 \\
\hline L112-16 & 21.80 & 18.12 & 20.75 & 14.39 & 29.77 & 29.30 & 20.64 & 9.09 & 29.55 & 25.93 & 18.98 & 81.022 \\
\hline L1112-20 & 30.41 & 50.23 & 36.87 & 45.43 & 21.49 & 22.07 & 36.96 & 44.44 & 19.51 & 22.22 & 34.73 & 65.269 \\
\hline IPL-221 & 24.39 & 6.87 & 20.58 & 15. & 5.03 & 17.58 & 13.02 & 11.46 & 4.0 & 16.67 & 10.23 & 9.773 \\
\hline IPL-324 & 2.4 & 13.5 & 5 & 4.44 & 5 & 6. & A & 4.82 & 5.66 & J & 5. & .268 \\
\hline IPL-325 & 22.50 & 14.87 & 20.43 & 6.01 & 9.14 & 8.11 & 7.20 & 4.04 & 10.00 & 11.36 & 7.39 & 92.611 \\
\hline PL-099 & 15.88 & 12.41 & 15.09 & 12.02 & 25.27 & 42.79 & 20.06 & 8.60 & 14.29 & 38.89 & 16.22 & 83.784 \\
\hline PL-100 & 28.32 & 31.29 & 28.95 & 8.85 & 35.02 & 33.91 & 18.92 & 10.58 & 28.00 & 30.30 & 18.72 & 81.283 \\
\hline ILL-10805 & 10.85 & 20.64 & 14.03 & 12.04 & 22.17 & 12.64 & 15.39 & 11.11 & 16.18 & 9.09 & 12.44 & 87.560 \\
\hline ILL-10951 & 12.99 & 12.86 & 12.98 & 11.81 & 14.77 & 12.58 & 12.77 & 10.71 & 13.33 & 25.00 & 14.29 & 85.714 \\
\hline ILL-10808 & 26.05 & 12.12 & 22.17 & 23.77 & 15.07 & 22.52 & 21.12 & 14.94 & 20.83 & 20.00 & 17.58 & 82.424 \\
\hline ILL-10922 & 33.19 & 49.87 & 38.18 & 25.70 & 22.31 & 46.71 & 27.70 & 9.91 & 14.67 & 41.94 & 19.36 & 80.645 \\
\hline L-4591 & 8.93 & 5.42 & 7.76 & 8.00 & 27.34 & 26.88 & 17.63 & 10.35 & 26.32 & 20.00 & 17.24 & 82.759 \\
\hline L-4581 & 38.72 & 10.89 & 32.63 & 14.98 & 18.24 & 43.22 & 19.45 & 6.98 & 12.90 & 42.11 & 16.13 & 83.871 \\
\hline KLS-113 & 30.51 & 10.28 & 25.99 & 47.04 & 17.11 & 21.05 & 37.92 & 36.84 & 12.50 & 27.27 & 29.23 & 70.769 \\
\hline LH-07-27 & 30.06 & 9.48 & 24.56 & 21.66 & 19.44 & 27.67 & 21.83 & 15.46 & 14.52 & 28.21 & 17.54 & 82.464 \\
\hline LH-08-10 & 11.93 & 33.20 & 17.64 & 3.74 & 18.64 & 32.54 & 10.57 & 6.94 & 18.18 & 33.33 & 15.75 & 84.247 \\
\hline ILL-10258 & 13.40 & 10.95 & 12.86 & 12.15 & 5.22 & 16.33 & 10.71 & 13.33 & 6.67 & 28.13 & 14.47 & 85.526 \\
\hline K-75 & 19.77 & 32.33 & 22.62 & 7.12 & 9.16 & 13.93 & 8.50 & 5.10 & 10.42 & 11.11 & 7.51 & 92.486 \\
\hline RVL-48 & 42.79 & 39.35 & 42.11 & 12.85 & 32.41 & 42.08 & 21.90 & 9.68 & 16.67 & 36.36 & 16.67 & 83.333 \\
\hline VL-142 & 18.83 & 2.04 & 14.04 & 24.94 & 16.41 & 23.86 & 22.35 & 18.42 & 13.64 & 22.64 & 18.03 & 81.974 \\
\hline DPL-62 & 42.50 & 28.32 & 38.53 & 26.98 & 28.41 & 26.10 & 27.33 & 18.18 & 10.71 & 27.08 & 17.46 & 82.545 \\
\hline PLG-109 & 18.60 & 36.43 & 23.97 & 6.53 & 11.73 & 28.42 & 10.52 & 9.22 & 9.09 & 23.33 & 12.36 & 87.640 \\
\hline DL-11-4 & 33.03 & 11.63 & 28.46 & 16.44 & 7.46 & 26.97 & 15.32 & 12.64 & 6.67 & 30.30 & 14.55 & 85.455 \\
\hline LL-1114 & 25.06 & 36.30 & 27.98 & 14.46 & 29.49 & 22.34 & 19.76 & 15.15 & 17.39 & 18.87 & 16.74 & 83.258 \\
\hline LL-1146 & 8.65 & 10.58 & 9.16 & 7.51 & 7.94 & 7.47 & 7.62 & 5.94 & 8.07 & 7.84 & 7.01 & 92.991 \\
\hline
\end{tabular}


International Journal of Bio-resource and Stress Management 2017, 8(4):539-547

\begin{tabular}{lcccccccccccc}
\hline $\begin{array}{l}\text { Geno- } \\
\text { types }\end{array}$ & $\begin{array}{c}\mathrm{RL} \\
(\mathrm{cm})\end{array}$ & $\begin{array}{c}\mathrm{SL} \\
(\mathrm{cm})\end{array}$ & $\begin{array}{c}\mathrm{TL} \\
(\mathrm{cm})\end{array}$ & $\begin{array}{c}\text { RFW } \\
(\mathrm{mg})\end{array}$ & $\begin{array}{c}\text { SFW } \\
(\mathrm{mg})\end{array}$ & $\begin{array}{c}\text { LFW } \\
(\mathrm{mg})\end{array}$ & $\begin{array}{c}\text { TFW } \\
(\mathrm{mg})\end{array}$ & $\begin{array}{c}\text { RDW } \\
(\mathrm{mg})\end{array}$ & $\begin{array}{c}\text { SDW } \\
(\mathrm{mg})\end{array}$ & $\begin{array}{c}\text { LDW } \\
(\mathrm{mg})\end{array}$ & $\begin{array}{c}\text { TDW } \\
(\mathrm{mg})\end{array}$ & DTE\% \\
\hline LL-1204 & 21.23 & 21.67 & 21.32 & 17.83 & 30.31 & 32.11 & 22.46 & 11.11 & 22.64 & 28.57 & 17.35 & 82.653 \\
KLS-107 & 56.38 & 42.57 & 52.12 & 40.98 & 40.56 & 36.71 & 40.23 & 22.62 & 20.83 & 30.95 & 24.14 & 75.862 \\
L-1204 & 20.69 & 15.58 & 19.07 & 15.69 & 14.09 & 22.06 & 16.02 & 12.15 & 16.07 & 17.95 & 14.36 & 85.644 \\
L-4076 & 13.77 & 12.86 & 13.47 & 10.08 & 23.73 & 10.46 & 14.73 & 7.97 & 8.14 & 15.79 & 9.77 & 90.234 \\
L-4590 & 17.31 & 11.80 & 15.54 & 15.21 & 4.14 & 14.71 & 12.07 & 8.43 & 11.32 & 15.79 & 10.92 & 89.080 \\
L1112-10 & 31.01 & 26.71 & 29.74 & 22.95 & 29.19 & 22.45 & 25.05 & 15.79 & 20.00 & 22.22 & 18.18 & 81.818 \\
L1112-17 & 19.90 & 18.02 & 19.51 & 10.59 & 20.45 & 21.24 & 14.75 & 7.92 & 9.68 & 19.05 & 10.73 & 89.268 \\
L1112-14 & 27.46 & 33.93 & 29.35 & 30.83 & 32.58 & 23.32 & 30.58 & 22.41 & 19.44 & 26.83 & 22.27 & 77.729 \\
L-10-331 & 36.03 & 28.97 & 34.07 & 15.11 & 30.13 & 22.04 & 20.67 & 11.77 & 13.64 & 18.18 & 13.43 & 86.567 \\
\hline
\end{tabular}

RL: root length; SL: shoot length, TL: total length; RFW: root fresh weight; SFW: shoot fresh weight; LFW: leaf fresh weight; TFW: total fresh weight; RDW: root dry weight; SDW: shoot dry weight; LDW: leaf dry weight; TDW: total dry weight; SE $(m)$ : standard error (mean); CD: critical difference

growth. Therefore, one or the other causes might have played role towards reduction of morphological characters of the seedling s under study due to imposition of stress.

\subsection{Shoot fresh weight}

Due to water stress, L-4076 recorded the highest $(189.667 \mathrm{mg})$, and KLS-107 exhibited the lowest ( $85 \mathrm{mg}$ ) shoot fresh weight. Generally the genotypes those exhibited significantly higher mean for shoot length under control or under treatment, revealed similar result in case of shoot fresh weight also. When the performance of this character due to treatment is compared with root fresh weight, it was observed that most of the genotypes that had significantly lower mean in root fresh weight could do so in case of shoot fresh weight also. All genotypes revealed reduced mean due to treatment than control for this character. But the lowest reduction $(4.138 \%)$ was recorded in the genotype L-4590 and the highest (47.849\%) was recorded in the genotype LP- 112 .

\subsection{Leaf fresh weight}

ILL-10922 recorded the highest $(106.333 \mathrm{mg}$ ) value and LP112 and L-112-13 recorded the lowest ( $44 \mathrm{mg}$ ) mean for this character under control. In case of treatment, L-4076 recorded the highest $(91.333 \mathrm{mg})$ mean and LP-112 produced the lowest (30.667 mg) mean. In all the genotypes leaf fresh weight reduced due to imposition of water stress. However, highest reduction (46.708\%) was recorded in the genotype ILL-10922 and lowest $(6.977 \%)$ in the genotype IPL-324. Such differential response of different genotypes towards water stress reveals their differential genetic makeup. Naidu et al. (2001) found that relative water content of leaves (RWC) and leaf area per plant decreased in all the genotypes under drought stress situations but proline content increased. Such accumulated proline might have contributed towards osmotic adjustment which plays a major role in maintaining turgor over fluctuating soil water potentials. Therefore, some osmo-regulator might have rendered turgor to exhibit resistance to drought situation in the genotypes that revealed significantly higher mean values for this character under water stress condition.

\subsection{Total fresh weight}

Under control condition, DPL-62 recorded the highest ( $833 \mathrm{mg}$ ) and LP-112 recorded the lowest $(425.667 \mathrm{mg})$. This appears to be obvious since DPL-62 produced highest root and shoot fresh weight under control condition. In case of treatment, PLG109 recorded the highest $(655 \mathrm{mg})$, while, LP-112 recorded the lowest $(268 \mathrm{mg})$. It may be mentioned here that LP-112 produced the lowest RFW under both control and treatment conditions as well. The mean values due to treatment reduced in all the genotypes, such reduction was highest in case of KLS$107(40.228 \%)$ and lowest in the genotype IPL-324 (4.954\%). In general most of the genotypes those exhibited significantly higher mean for root fresh weight also gave the similar result for total fresh weight also. Interestingly most of such genotypes produced significantly higher SFW and LFW also.

\subsection{Root dry weight}

DPL-62 exhibited the highest (47.667 mg), LP-112 exhibited the lowest $(21.667 \mathrm{mg})$ mean root dry weight. In case of treated population, PLG-109 recorded the highest (42.667 $\mathrm{mg}$ ), while LP-112 recorded the lowest (17.333 mg). Generally, the genotypes that produced significantly higher mean in case of root fresh weight under control and treatment performed similarly in case of dry weight also. The relative reduction due to treatment was recorded lowest (4.04\%) for the genotype IPL-325 and the highest (44.444\%) for the genotype L111220. Decrease in root dry weight because of water stress has earlier been reported by Nasab (2011) in lentil. Such decrease might have been either due to the production of reduced photosynthates under water deficit condition or due to reduced rate of translocation of photosynthate.

\subsection{Shoot dry weight}

The genotype L-4076 recorded the highest $(28.667 \mathrm{mg})$, while the genotype L1112-12 exhibited the lowest $(13 \mathrm{mg})$ in 
control. In case of PEG imposed water stress, L-4076 recorded the highest (26.333 $\mathrm{mg}$ ) and LP-112 and L112-16 recorded lowest mean value $(10.333 \mathrm{mg})$. Here it may be noticed that seventeen out of twenty-one genotypes in case of control and sixteen out of nineteen genotypes in case of treatment exhibiting significantly higher mean for shoot dry weight also recorded significantly higher mean for root dry weight. Therefore, it may be inferred that genotypes exhibiting higher shoot dry weight also exhibit higher root dry weight. In the present study, the effect of osmotic water potential and interaction between genotypes and the osmotic potential on fresh and dry weight of shoot were significant. On the other hand, significant drought and genotype interaction indicated that different genotype respond differentially to drought stress i.e. their differential genetic makeup might have inflicted such results. The greatest reduction in shoot dry weight was observed in LP-112 and the lowest in IPL-221 amounting to $45.614 \%$ and $4 \%$ respectively. Some genotypes that produced significantly lower mean for fresh weight revealed similar result for dry weight of this character seems obvious. But some genotypes like LL-12-10 and LL-1114 that produced significantly lower mean for fresh weight of this character due to treatment but the dry weight become higher seems conspicuous. The reverse case was also observed where some genotypes showing significantly higher mean for fresh weight exhibited significantly lower mean for dry weight for this character. Decline in seedling dry weight in response to low water potential is a consequence of decline in weight of mobilized seed reserve due to low water uptake by the germinating seeds (Soltani et al., 2006).

\subsection{Leaf dry weight}

Leaf is one of the most important characters considered in this study since it regulates water content of the whole plant body. Besides, the photosynthate is mainly produced in this part of the plant which ultimately results in dry matter production in the plant body. When the character leaf dry weight was considered, it was noticed ILL-10922 recorded the highest (20.667 mg) value, while PL-406 recorded the lowest (6.667 $\mathrm{mg}$ ) under no stress. In case of treatment, L-4076 recorded the highest mean (16 $\mathrm{mg}$ ) and DL-11-5 recorded the lowest (5.667 $\mathrm{mg}$ ). In case of relative reduction due to treatment, the highest value was recorded in the genotype L-4581 (42.105\%) and the lowest in the genotype PL-406 (5\%).

\subsection{Total dry weight}

Considering this character, DPL-62 recorded the highest mean $(91.667 \mathrm{mg}$ ) and L112-16 exhibited the lowest mean value $(45.667 \mathrm{mg})$. In case of treatment, PLG-109 recorded the highest (78 mg) and LP-112 recorded the lowest (33.667 $\mathrm{mg}$ ) mean for this character. The results showed that the mean root fresh and dry weight were greater than mean shoot fresh and dry weight thus indicating shoot growth to be more sensitive than root growth to water stress (Yucel et al., 2010). The reasons for such result may be that root is the first organ emerged from the seed, therefore its growth is faster than shoot growth and also shoot does not have any direct contact with water resource because of its late emergence and location on the seed. Considering \% reduction of mean due to treatment, it was noticed maximum in the genotype L-1112-20 (34.731\%) while the lowest (5.333\%) was recorded in the genotype PL-406.

The genotypes showing lower RRP had inherent capacity to resist the water stress imposed by PEG under study and vice versa. All the genotypes showed variable response to PEG imposed drought stress, so they had differential rate of reduction for the seedling traits under study. The genotype PL406 showed lowest RRP for root length (2.09\%), leaf dry weight (5.00\%) and total dry weight (5.33\%). VL-142 exhibited lowest RRP shoot length (2.04\%). The genotype IPL-324 showed lowest RRP for total length (5.55\%) and total fresh weight (4.95\%). LH-08-10 exhibited lowest RRP for root fresh weight (3.74\%). L-4596 showed lowest RRP for shoot fresh weight (4.14\%). IPL-325 exhibited lowest RRP for root dry weight (4.04\%). IPL-221 exhibited lowest RRP for shoot dry weight (4.00\%). This is in accordance with Turk et al., 2004, who were of opinion that the genotypes which performed better under osmotic stress in terms of lesser reduction in various aspects of growth might be related to their drought tolerance.

\subsection{Drought tolerance efficiency}

Since drought tolerance efficiency is a ratio of mean of total dry weight observed under treatment and that under control therefore higher the value for this character desirable will be the genotype. Thus this is the most important character to be considered in the present study. It may be noticed that among the forty-eight genotypes, PL-406 (94.667\%) exhibited the highest drought tolerance efficiency followed by IPL324 (94.268\%), LL-1146 (92.991\%), IPL-325 (92.611\%), K-75 (92.486\%) and L-4076 (90.234\%), whileL1112-20 (65.269\%) exhibited the lowest drought tolerance efficiency followed by LP-112 (68.243\%), ILL-10803 (70.352\%), KLS-113 (70.769\%), KLS-107 (75.862\%) and L1112-14 (77.729\%). Among the genotypes that produced remarkably higher DTE, also revealed higher mean values for both fresh weight and dry weight of root. Drought tolerance efficiency is an important and reliable index for measurement of drought tolerance basing on drought tolerance efficiency, tolerant and susceptible genotypes were identified to be used for further study. Five genotypes viz., L1112-20, LP-112, ILL-10803, KLS-113 and KLS107 were selected as susceptible.

\subsection{Character association}

Correlation analysis reveals the mutual relationship among various traits defined by magnitude and direction. In breeding for water stress tolerance, different characters are considered rather than a single trait to achieve the required goal. The genotypic and phenotypic correlation co-efficient among eleven seedling characters obtained when grown under PEG imposed stress condition is presented in table 3 . The 
correlation values at both the genotypic and phenotypic levels indicate that none of the character pairs is negatively associated. The genotypic correlation values were higher than respective phenotypic ones indicating genetic control on the character. All the characters under present investigation exhibited significant positive association among each other at both genotypic and phenotypic levels. The character pairs exhibited significant value at phenotypic level.

It is needless to mention that accumulation of dry matter is the important objective in plant breeding; therefore, importance should be given on the characters which exhibit highly significant positive correlation with total dry matter. Accordingly, to improve dry matter production more emphasis needs to be given on root dry weight, total fresh weight, root fresh weight and root length. Under water stress condition, total dry weight attained a strong positive significant association with root dry weight followed by total fresh weight. Root dry weight revealed a high positive correlation with total fresh weight which exhibited highest significant positive correlation with root fresh weight. Ultimately it was confirmed that root character had played a major role towards total dry weight which is connected with drought

Table 3: Genotypic (G) and Phenotypic (P) correlation coefficient among different growth parameters at seedling stage of 48 lentil genotypes grown under drought condition

\begin{tabular}{|c|c|c|c|c|c|c|c|c|c|c|c|}
\hline Characters & & $\begin{array}{c}\mathrm{SL} \\
(\mathrm{cm}) \\
\end{array}$ & $\begin{array}{c}\mathrm{TL} \\
(\mathrm{cm})\end{array}$ & $\begin{array}{l}\text { RFW } \\
\text { (mg) }\end{array}$ & $\begin{array}{l}\text { SFW } \\
\text { (mg) }\end{array}$ & $\begin{array}{l}\text { LFW } \\
\text { (mg) }\end{array}$ & $\begin{array}{l}\text { TFW } \\
(\mathrm{mg}) \\
\end{array}$ & $\begin{array}{l}\text { RDW } \\
\text { (mg) }\end{array}$ & $\begin{array}{l}\text { SDW } \\
\text { (mg) }\end{array}$ & $\begin{array}{l}\text { LDW } \\
\text { (mg) }\end{array}$ & $\begin{array}{l}\text { TDW } \\
\text { (mg) }\end{array}$ \\
\hline \multirow[t]{2}{*}{$\mathrm{RL}(\mathrm{cm})$} & G & 0.515 & 0.953 & 0.177 & 0.314 & 0.162 & 0.243 & 0.105 & 0.189 & 0.010 & 0.120 \\
\hline & $P$ & $0.515^{* *}$ & $0.953^{* *}$ & $0.177^{*}$ & $0.313^{* *}$ & $0.161^{\mathrm{NS}}$ & $0.243^{* *}$ & $0.103^{\mathrm{NS}}$ & $0.183^{*}$ & $0.010^{\mathrm{NS}}$ & $0.119^{\mathrm{NS}}$ \\
\hline \multirow[t]{2}{*}{$\mathrm{SL}(\mathrm{cm})$} & G & & 0.751 & 0.015 & 0.520 & 0.230 & 0.198 & 0.052 & 0.356 & 0.194 & 0.196 \\
\hline & $P$ & & $0.751^{* *}$ & $0.015^{\mathrm{NS}}$ & $0.516^{* *}$ & $0.227^{* *}$ & $0.198^{*}$ & $0.051^{\mathrm{NS}}$ & $0.342^{* *}$ & $0.188^{*}$ & $0.194^{*}$ \\
\hline \multirow[t]{2}{*}{$\mathrm{TL}(\mathrm{cm})$} & G & & & 0.142 & 0.426 & 0.207 & 0.258 & 0.099 & 0.272 & 0.077 & 0.162 \\
\hline & $P$ & & & $0.142^{\mathrm{NS}}$ & $0.424^{* *}$ & $0.205^{*}$ & $0.257^{* *}$ & $0.097^{\mathrm{NS}}$ & $0.263^{* *}$ & $0.074^{\text {NS }}$ & $0.161^{\mathrm{NS}}$ \\
\hline \multirow[t]{2}{*}{ RFW (mg) } & G & & & & 0.473 & 0.628 & 0.947 & 0.892 & 0.649 & 0.609 & 0.827 \\
\hline & $P$ & & & & $0.467^{* *}$ & $0.622^{* *}$ & $0.946^{* *}$ & $0.874^{* *}$ & $0.620^{* *}$ & $0.588^{* *}$ & $0.821^{* *}$ \\
\hline \multirow[t]{2}{*}{ SFW (mg) } & G & & & & & 0.558 & 0.715 & 0.574 & 0.829 & 0.501 & 0.699 \\
\hline & $P$ & & & & & $0.558^{* *}$ & $0.713^{* *}$ & $0.541^{* *}$ & $0.819^{* *}$ & $0.496^{* *}$ & $0.693^{* *}$ \\
\hline \multirow[t]{2}{*}{ LFW (mg) } & G & & & & & & 0.762 & 0.647 & 0.751 & 0.891 & 0.809 \\
\hline & $P$ & & & & & & $0.759^{* *}$ & $0.612^{* *}$ & $0.734^{* *}$ & $0.876^{* *}$ & $0.799^{* *}$ \\
\hline \multirow[t]{2}{*}{ TFW (mg) } & G & & & & & & & 0.902 & 0.819 & 0.715 & 0.917 \\
\hline & $P$ & & & & & & & $0.876^{* *}$ & $0.795^{* *}$ & $0.698^{* *}$ & $0.911^{* *}$ \\
\hline \multirow[t]{2}{*}{ RDW (mg) } & G & & & & & & & & 0.761 & 0.689 & 0.941 \\
\hline & $P$ & & & & & & & & $0.686^{* *}$ & $0.636^{* *}$ & $0.922^{* *}$ \\
\hline \multirow[t]{2}{*}{ SDW (mg) } & G & & & & & & & & & 0.714 & 0.906 \\
\hline & $P$ & & & & & & & & & $0.697^{* *}$ & $0.883^{* *}$ \\
\hline \multirow[t]{2}{*}{ LDW (mg) } & G & & & & & & & & & & 0.847 \\
\hline & $\mathrm{P}$ & & & & & & & & & & $0.831^{* *}$ \\
\hline
\end{tabular}

"Significant at $(p=0.05)$ level; ${ }^{* *}$ Significant at $(p=0.01)$ level; NS: Nonsignificant

tolerant mechanism. In PEG mediated drought stress, all the traits except root length and total length attained significant positive correlation with total dry weight. Such non-significant relationship between root length and total dry weight may be because of the role played by root diameter, which was not studied in the present experiment. Importance should be given on the characters where highly significant positive correlation is observed between total dry matter production and the other associated characters. Results of the present experiment further reveals that to improve dry matter production more emphasis needs to be given on root dry weight, total fresh weight, and root fresh weight.

\subsection{Path analysis}

Correlation values illustrate the interrelationship between different characters; path coefficient splits the amount of interrelationship into direct and indirect effects. Genotypic path values revealing the association of total dry weight contributing characters, their direct and indirect effects are presented in Table 4. Path coefficient analysis was based on 
correlation coefficient using total dry weight as the dependent factor (effect) and fix; while other quantitative characters viz., root length, shoot length, total length, root fresh weight, shoot fresh weight, leaf fresh weight, total fresh weight, root dry weight, shoot dry weight and leaf dry weight played role as independent factors (causes). Thus, correlation coefficient of each independent quantitative character was partitioned into direct and indirect effects towards total dry weight. The residual effect was low, i.e. (0.06410) justifying the number of characters considered in the present experiment was adequate to explain the variation in path analysis. From the analysis, it was revealed that, fresh weight of root, shoot and leaf rendering negative direct effect with total dry weight under water stress showed significantly positive correlation with total dry weight. This might have been due to very high indirect positive effects of these characters via total fresh

Table 4: Path coefficient analysis showing direct (bold) and indirect effects of different characters grown under drought condition

\begin{tabular}{lccccccccccc}
\hline Characters & & $\begin{array}{c}\mathrm{SL} \\
(\mathrm{cm})\end{array}$ & $\begin{array}{c}\mathrm{TL} \\
(\mathrm{cm})\end{array}$ & $\begin{array}{r}\text { RFW } \\
(\mathrm{mg})\end{array}$ & $\begin{array}{r}\text { SFW } \\
(\mathrm{mg})\end{array}$ & $\begin{array}{r}\text { LFW } \\
(\mathrm{mg})\end{array}$ & $\begin{array}{r}\text { TFW } \\
(\mathrm{mg})\end{array}$ & $\begin{array}{r}\text { RDW } \\
(\mathrm{mg})\end{array}$ & $\begin{array}{r}\text { SDW } \\
(\mathrm{mg})\end{array}$ & $\begin{array}{c}\text { LDW } \\
(\mathrm{mg})\end{array}$ & $\begin{array}{c}\text { TDW } \\
(\mathrm{mg})\end{array}$ \\
\hline RL(cm) & 0.000 & 0.000 & 0.000 & -0.172 & -0.118 & -0.030 & 0.314 & 0.053 & 0.064 & 0.003 & $0.120 \mathrm{NS}$ \\
$\mathrm{SL}(\mathrm{cm})$ & 0.000 & 0.000 & 0.000 & -0.015 & -0.196 & -0.043 & 0.256 & 0.027 & 0.120 & 0.050 & $0.196^{*}$ \\
TL (cm) & 0.000 & 0.000 & 0.000 & -0.138 & -0.161 & -0.038 & 0.332 & 0.051 & 0.092 & 0.020 & $0.162^{\text {NS }}$ \\
RFW (mg) & 0.000 & 0.000 & 0.000 & -0.970 & -0.178 & -0.117 & 1.221 & 0.454 & 0.218 & 0.155 & $0.827^{* *}$ \\
SFW (mg) & 0.000 & 0.000 & 0.000 & -0.458 & -0.377 & -0.104 & 0.923 & 0.292 & 0.279 & 0.128 & $0.699^{* *}$ \\
LFW (mg) & 0.000 & 0.000 & 0.000 & -0.609 & -0.210 & -0.186 & 0.983 & 0.329 & 0.253 & 0.227 & $0.809^{* *}$ \\
TFW (mg) & 0.000 & 0.000 & 0.000 & -0.918 & -0.270 & -0.141 & 1.290 & 0.459 & 0.276 & 0.182 & $0.917^{* *}$ \\
RDW (mg) & 0.000 & 0.000 & 0.000 & -0.865 & -0.216 & -0.120 & 1.163 & 0.509 & 0.256 & 0.176 & $0.941^{* *}$ \\
SDW (mg) & 0.000 & 0.000 & 0.000 & -0.629 & -0.312 & -0.139 & 1.056 & 0.387 & 0.337 & 0.182 & $0.906^{* *}$ \\
LDW (mg) & 0.000 & 0.000 & 0.000 & -0.590 & -0.189 & -0.165 & 0.922 & 0.351 & 0.241 & 0.255 & $0.847^{* *}$ \\
\hline
\end{tabular}

Residual are 0.06410; ${ }^{*}$ Significant at $(p=0.05)$ level; ${ }^{* *}$ Significant at $(p=0.01)$ level; NS: Nonsignificant

weight, root dry weight, shoot dry weight and leaf dry weight. Homayoun et al. (2011) stated that due to decreased water potential shoot growth is more affected than root growth. The direct effect of root dry weight was observed to attain the highest value in control condition whereas total fresh weight had put highest direct effect followed by root dry weight in case of treated population. This result suggests the importance of root dry weight in both the conditions. Significantly positive and high correlation between total fresh weight, shoot dry weight and leaf dry weight with total dry weight might have been the consequence of direct effect of the former characters on the dependant character. The direct effects of root length, shoot length and total length were obtained to be zero. But Muscolo et al. (2013) identified root length as rapid selection criteria in lentil for drought tolerance. In water deficit situation, shoot length showed positive significant correlation due the indirect effects of total fresh weight, root dry weight, shoot dry weight, and leaf dry weight. However, the highest negative direct effect of -0.148 was noticed in case of root fresh weight. The highest positive direct effect was recorded in case of total fresh weight (1.290). Therefore, in spite of negative direct effect positive correlation might have appeared due to superseding indirect effect of the other characters. Therefore, in case of such characters much emphasis should be given on the characters whose indirect effect is very high. The nature of response due to drought by a genotype will change with environment. Thus, screening of genotypes is important prior to its utilization in breeding programme for drought resistance.

\section{Conclusion}

Imposition of water stress all the lentil genotypes exhibited a decrease in all root and shoot traits at seedling stage. Basing upon drought tolerance efficiency, five genotypes viz., PL-406, IPL-324, LL-1146, IPL-325 and K-75 were selected as tolerant and five genotypes viz., L1112-20, LP-112, ILL-10803, KLS-113 and KLS-107 were selected as susceptible. From this research of lentil crop under PEG imposed drought stress, root dry weight and total fresh weight were reported as selection criteria for drought tolerance at seedling stage.

\section{Literature cited:}

Chapman, S.C., Chakraborty, S., Dreccer, M.F., Howden, S.M., 2012. Plant adaptation to climate change-opportunities and priorities in breeding. Crop Pasture Science 63, 251-268.

Dhanda, S.S., Sethi, G.S., Behl, R.K., 2004. Indices of drought tolerance in wheat genotypes at early stages of plant growth. Journal of Agronomy and Crop Science 190, 6-12.

Dhuppar, P., Biyan, S., Chintapalli, B., Rao, S., 2012. Lentil 
Crop Production in the Context of Climate Change: An Appraisal. Indian Research Journal of Extension Education 2(Special Issue), 33-35.

FAOSTAT, 2014. Agricultural Data on Primary Crops. http:// www.fao.org/faostat

Farshadfar, E., Farshadfar, M., Dabiri, S., 2012. Comparison between effective selection criteria of drought tolerance in bread wheat landraces of Iran. Annals of Biological Research 3(7), 3381-3389.

Fisher, R.A., Maurer, R., 1978. Drought resistance in spring wheat cultivars: I. Grain yield responses. Australian Journal of Agricultural Research 29, 897-912.

Fouad, M., Imtiaz, M., Kumar, S., Malhotra, R., 2011. Breeding food legumes for enhanced drought and heat tolerance to cope with climate change. In 'Food Security and Climate Change in Dry Areas. Proceedings of International Conference'. Solh, M., Saxena, M.C. (Eds.), (ICARDA: Aleppo, Syria), 244-254.

Franco, J.A., Banon, S., Vicente, M.J., Miralles, J., MartinezSanchez, J.J., 2011. Root development in horticultural plants grown under abiotic stress conditions-A review. Journal of Horticultural Science and Biotechnology 86, 543-556.

Homayoun, H., Parisa, M., Daliri, M.S., 2011. Study of Salinity Stress Effect on Two Potato (Solanum tuberosum L.) Cultivars In vitro. American-Eurasian Journal of Agricultural and Environtal Science 11(5), 729-732.

Kulkarni, M., Deshpande, U., 2007. In Vitro screening of tomato genotypes for drought resistance using polyethylene glycol. African Journal of Biotechnology 6, 691-696.

Luo, L.J., 2010. Breeding for water saving and drought resistance rice (WDR) in China. Journal of Experimental Botany 61, 3509-3517.

Maryam, N., Mahmood, D., Alireza, I., Ali, B., 2013. Changes of Sorghum growth in response to drought and allelopathy stresses. Annals of Biological Research 4(6), 18-22.

Mbarek, K.B., Gargouri, K.E., Boubaker, M., 2013. Screening of osmotic water stress tolerant chickpea genotypes (Cicer arietinum L.) on the basis of germination parameters and accumulated soluble sugars and proline content.
Octa Journal of Environmental Research 1(2), 117-128. Muscolo, A., Sidari, M., Anastasi, U., Santonoceto. C., Maggio., A., 2014. Effect of PEG-induced drought stress on seed germination of four lentil genotypes. Journal of Plant Interactions 9(1), 354-363.

Naidu, T.C.M., Raju, N., Narayanan, A., 2001. Screening of drought tolerance in greengram (Vigna radiata $\mathrm{L}$. Wilczek) genotypes under receding soil moisture. Indian Journal of Plant Physiology 6(2), 197-201.

Nasab, A.D.M., 2011. Effects of water potential on germination and seedling growth of two varieties of lentil (Lens culinaris, Medick.). International Journal of Agriculture and Crop Sciences 3(2), 61-64.

Salehpour, M., Ebadi, A., Izadi, M., Jamaati-e-Somarin, S., 2009. Evaluation of water stress and nitrogen fertilizer effects on relative water content, membrane stability index, chlorophyll and some other traits of lentils (Lens culinaris L.) under hydroponics conditions. Research Journal of Environmental Sciences 3(1), 103-109.

Sarker, A., Kumar, S., 2011. Lentils in production and food systems in West Asia and Africa. International Centre for Agricultural Research in the Dry Areas (ICARDA), Aleppo, Syria. Grain Legumes 57, 46-48.

Singh, D., Singh, C.K., Taunk, J., Tomar, R.S.S., Chaturbedi, A.K., Gaikwad, K., Pal, M., 2017. Transcriptome analysis of lentil (Lens culinaris Medikus) in response to seedling drought stress. BMC Genomics 18, 206

Soltani, A., Robertson, M.J., Manschadi, A.M., 2006. Modelling chickpea growth and development: Nitrogen accumulation and use. Field Crop Research 99, 24-34.

Turk, A.M., Rahman, A., Tawaha, M., Lee, K.D., 2004. Seed germination and seedling growth of three lentil cultivars under moisture stress. Asian Journal of Plant Sciences 3(3), 394-397.

Yucel, D.O., Anlarsal, A.E., Nart, D., Yucel, C., 2010. Effect of drought stress on early seedling growth of Chickpea (Cicer arietinum L.) genotypes. World Applied Sciences Journal 11(4), 478-485. 